\title{
Circadian rhythms in infectious diseases: Do they matter?
}

\author{
Denis Beauchamp PhD, Gaston Labrecque PhD
}

\begin{abstract}
D Beauchamp, G Labrecque. Circadian rhythms in infectious diseases: Do they matter? Can J Infect Dis 1999;10(Suppl C):61C-68C.

The present paper reviews the importance of the time of day in medicine, with a special emphasis on infectious diseases and antibiotics. Data were obtained from scientific journals following a literature search and from studies carried out in the authors' laboratory. Data indicating that the signs and symptoms of disease do not appear at random over a $24 \mathrm{~h}$ period are now available. For example, asthma occurs usually at night, while myocardial infarction or anginal attacks occur in the early morning hours. Very little data are available on infectious diseases, and most studies were carried out on the pharmacokinetics and toxicity of antibiotics. These data suggest that antimicrobial agents are eliminated more rapidly when injected during the activity period of animals or humans. It is also noteworthy that aminoglycosides and amphotericin B induced less toxicity during the activity period of laboratory animals or patients, and highest toxicity occurred during the sleeping period. This is particularly evident with data on aminoglycosides. Temporal variations were also observed in the effectiveness of aminoglycosides, but these data were found only in animal models of infectious diseases. Temporal variations in the pharmacokinetics, toxicity and effectiveness of antibiotics may lead to a more rational use of medications in patients.
\end{abstract}

Key Words: Antibiotics; Circadian rhythms; Infectious diseases; Pharmacokinetics; Toxicity

\section{Rythmes circadiens dans les maladies infectieuses : ont-ils une importance?}

RÉSUMÉ : Le présent article examine l'importance de l'heure du jour en médecine, en portant une attention spéciale aux maladies infectieuses et aux antibiotiques. Les données ont été recueillies à la suite d'une recherche dans la littérature scientifique et dans des études menées dans le laboratoire de l'auteur. On a maintenant à notre disposition des données démontrant que les signes et les symptômes de la maladie n'apparaissent pas au hasard sur une période de 24 heures. Par exemple, l'asthme survient habituellement la nuit, alors que l'infarctus du myocarde ou les crises d'angine surviennent aux petites heures du matin. Il n'existe que très peu de données sur les maladies infectieuses, et la plupart des études réalisées portent sur la pharmacocinétique et la toxicité des antibiotiques. Ces données laissent à penser que les agents antimicrobiens sont éliminés plus rapidement lorsqu'ils sont injectés pendant la période d'éveil des animaux ou des humains. On remarque aussi que les aminoglycosides et l'amphotéricine B se sont révélés moins toxiques pendant la période d'éveil d'animaux de laboratoire ou de patients, et le plus toxiques pendant la période de sommeil. Ceci est très net dans les données recueillies sur les aminoglycosides. Des variations temporelles ont aussi été observées dans l'efficacité des aminoglycosides, mais elles provenaient de modèles animaux de maladies infectieuses. Les variations temporelles dans la pharmacocinétique, la toxicité et l'efficacité des antibiotiques pourraient conduire à une utilisation plus rationnelle des médicaments chez les patients. 
$\mathrm{T}$ he concept of homeostasis is the basis of our understanding of the functions of the human body. It has been taught that a stable 'milieu intérieur' must be maintained over time for survival, and that this is achieved by specific feedback mechanisms. Changes in body physiology between sleep and waking states has been taught, and some clinicians have observed that diseases that typically occur in the spring, such as hay fever and asthma, are different than those that occur in the fall. However, it was generally thought that the probability of exacerbation of acute and chronic diseases or the occurrence of diseases and mortality was about equal over a $24 \mathrm{~h}$ period. It was also assumed that the effects of medications and pharmacokinetic processes were constant over day or night. Thus, the idea that time is an important feature in medicine has not been fully considered.

Chronobiology studies the fluctuation of biological functions and processes over time. Biological rhythms have been described in parameters related to physiology, pathology and more recently in the effects and kinetics of medications, including antibiotics. These findings are now being incorporated in clinical medicine.

The present review characterizes biological rhythms and provides examples to illustrate circadian rhythms in different pathologies. Data indicating the importance of time of day in infectious diseases in the effects and pharmacokinetics of antibiotics are presented.

\section{BIOLOGICAL RHYTHMS: DEFINITIONS AND SYNCHRONIZATION}

When physiological parameters are monitored repeatedly, it is evident that they are not static over time. On the contrary, most parameters vary in a predictable manner as rhythms of definite periods. The spectral analysis of human biological rhythms indicates that they can be divided into three categories.

- Ultradian rhythms have a range of periods (ie, time between two peaks) of 30 mins to $20 \mathrm{~h}$. Episodic secretion of hormone and the progression of sleep stages during the night are examples of this category of rhythms.

- Infradian rhythms have a period of low frequency, with monthly or yearly cycles. Menstruation in women and the annual appearance of hay fever are examples of this type of rhythm.

- Circadian rhythms have a period in a range of about $24 \mathrm{~h}$. These rhythms are best known to clinicians. Examples include the morning rise of heart rate or blood pressure and the higher plasma cortisol levels observed at the time of daily transition from sleep to activity.

This paper focuses on circadian rhythms because physicians are most familiar with them and they are the biological rhythms most often encountered in clinical situations.

Biological rhythms are a genetically inherited trait, but they are controlled by environmental time cues termed syn-

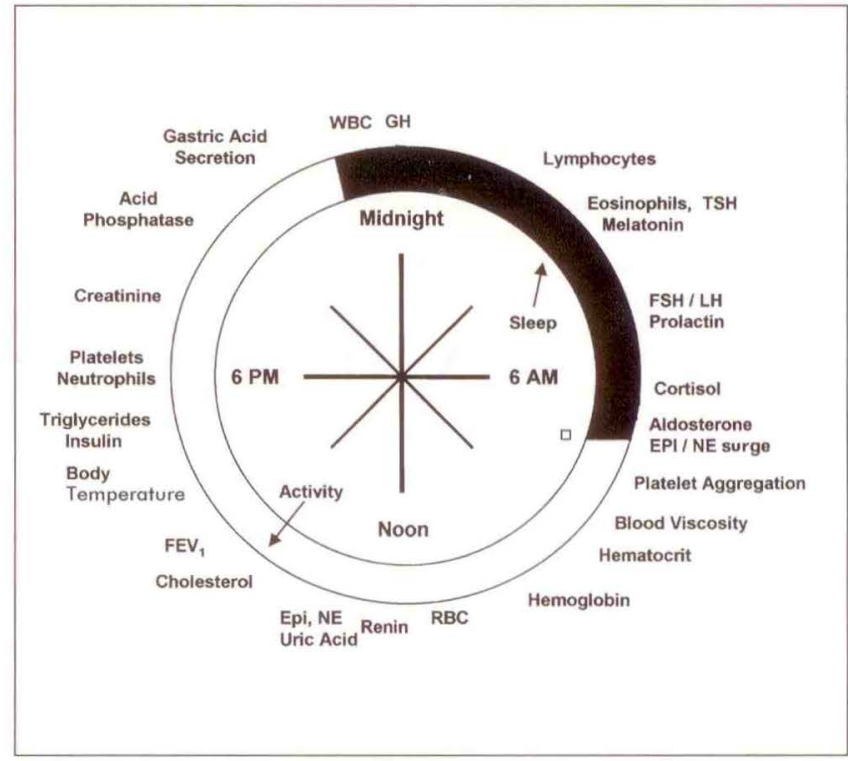

Figure 1) Peak time in physiological parameters. The peak time of selected circadian rhythms in human physiology is displayed in the form of a $24 \mathrm{~h}$ clock diagram with reference to the sleep 111:00 to 07:00) and the diurnal activity cycle. For example, plasma melatonin is highest in the middle of the night, while cortisol levels peak at the time of rising. Blood viscosity is higher in the morning and forced expiratory volume in $1 \mathrm{~s}$, triglycerides or cholesterol peaks occur in the afternoon. Epi Epinephrine; FEV 1 Forced expiratory volume in $1 \mathrm{~s}$; FSH follicle-stimulating hormone; GH Growth hormone; LH Luteinizing hormone; NE Norepinephrine; RBC Red blood (cell) count; TSH Thyroid-stimulating hormone; WBC White blood (cell) count. Data from reference 50

chronizers or zeitbergers. The strongest synchronizers are the wake-sleep routine for humans and the light-dark cycle for laboratory animals. These synchronizers do not create rhythms, but set the inherited pacemaker circadian timekeeping systems to $24 \mathrm{~h}$ each day. For example, plasma cortisol peaks at the beginning of the day both in those who work during the day and in those who work durning the night; however, the clock time for peak plasma cortisol differs in each group of individuals because they get up at different times of the day. Thus, it is the biological time of the individuals that is pertinent, not the hour by the clock.

\section{BIOLOGICAL RHYTHMS IN HEALTH AND DISEASE}

In the past 40 years, many investigators were able to characterize biological rhythms of physiological parameters. Figure 1 presents the time of day where peak levels were found for a series of parameters in laboratory medicine. For example, gastric acid secretion, white blood cells, prolactin, melatonin, eosinophils, adrenocorticotropic hormone (ACTH), folliclestimulating hormone and luteinizing hormone, all peak at specific times during the sleeping period. On the other hand, cortisol, aldosterone, testosterone, platelet adhesiveness and blood viscosity are highest early in the morning. Hematocrit, red blood cells and airway calibre are highest in the afternoon. Finally, insulin, cholesterol, triglycerides, number of platelets, acid phosphatase and uric acid are highest later in the afternoon or during the evening. Thus, it is possible to determine a 


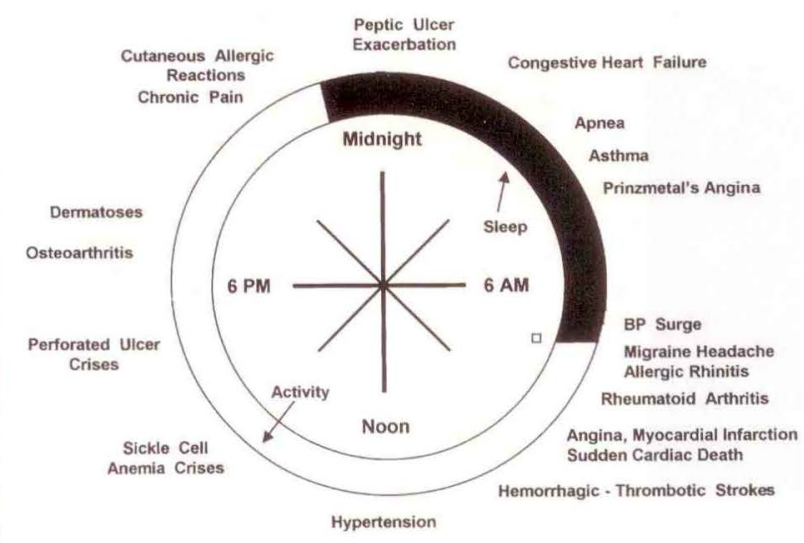

Figure 2) Peak time in the signs and symptoms of diseases. Using the $24 \mathrm{~h}$ clock display, the figure indicates that the signs and symptoms of many diseases are likely to be worst at a specific time of day or night. For example, asthma is worst during the sleeping period, while cardiovascular events are more frequent in the morning, and osteoarthritic pain peaks early in the evening. BP Blood pressure. Reproduced with permission from reference 1

temporal organization for the physiological processes. The cell is unable to do everything at the same time; thus, its activities are programmed during the $24 \mathrm{~h}$ period to assure the well-being of the body (1).

Figure 2 presents the circadian rhythms of diseases and indicates the peak time for signs and symptoms of different diseases. Physicians in the emergency room know that asthma attacks most often occur late in the evening and in the middle of the night. This is supported by a study including 1641 patients that showed that asthma attacks are more prevalent between 01:00 and 04:00 than at any other time of day (2). Physicians are also becoming aware that myocardial infarction (MI) occurs more frequently during the early morning hours. In fact, the risk of having an MI attack is much higher between 05:00 and 12:00 than at any other time of day (3). Similar data were found with sudden cardiac death and with different cardiovascular diseases, including angina attacks (4-6) and stroke (7). It is interesting to note that there is a morning surge in blood pressure and heart rate (8), and platelets aggregate more readily in the morning than at any other time of day (3). These examples in cardiology indicate that diseases are influenced by the circadian time structure. This is rarely taken into account in everyday medicine because clinicians believe that the symptoms of disease occur randomly over the $24 \mathrm{~h}$ period. Data on biological rhythms in health and disease will change this perception.

\section{BIOLOGICAL RHYTHMS IN INFECTIOUS DISEASES}

Seasonal changes in the incidence of infectious diseases are well known to physicians, but very few studies have been done on biological rhythms in infectious processes. Studies

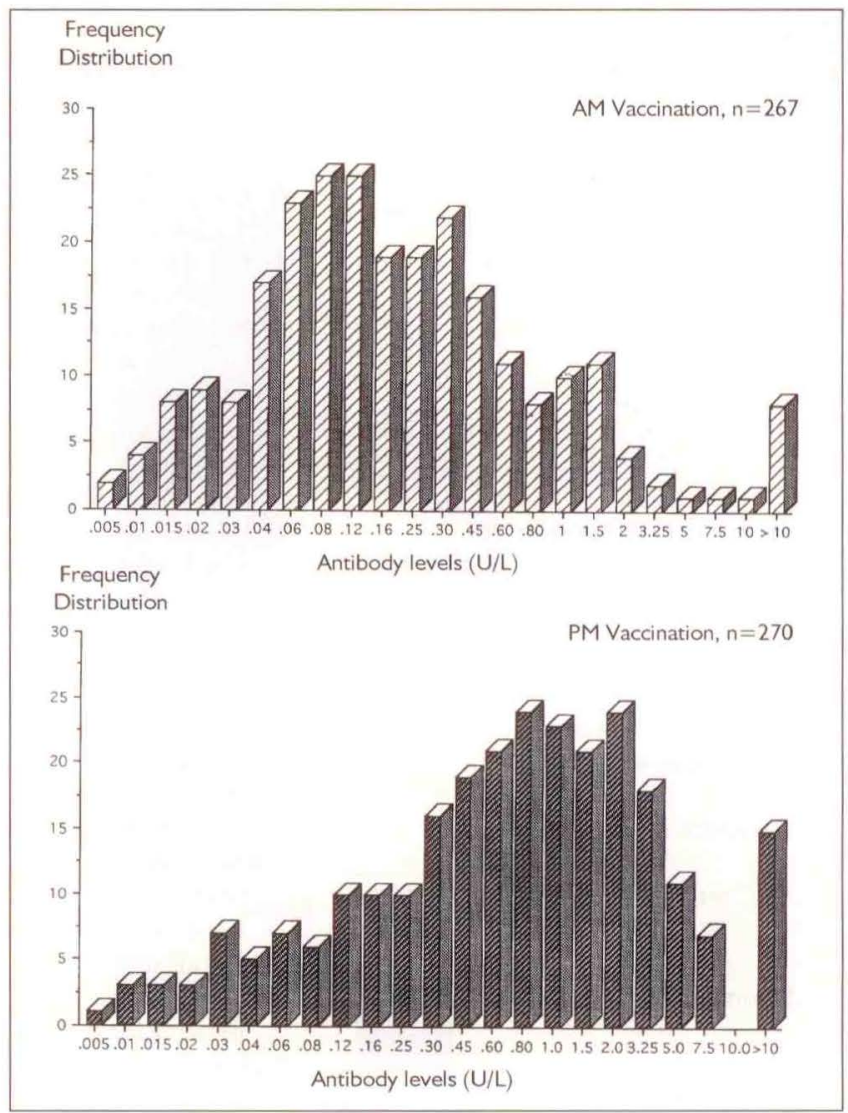

Figure 3) Frequency distribution of the antibody levels after three injections of hepatitis B vaccine in the morning (07:30 to 09:30) and in the afternoon (13:00 to 15:00) to hospital employees. Reproduced with permission from reference 12

conducted 40 years ago by Halberg (9) indicated that mice were more susceptible to the administration of the same dose of Escherichia coli endotoxin at certain hours of the day. Endotoxin injection in the middle of the activity period killed $20 \%$ of the mice injected, while $80 \%$ of the animals died when they were injected at the end of the resting period. The diurnal variations in the human response to Salmonella abotus equi endotoxin were studied recently in healthy volunteers (10). Results indicated that subjects who received endotoxin in the evening, when endogenous glucocorticoid levels were low, showed about twice the increase in rectal temperature, plasma ACTH and cortisol levels as those who received endotoxin $12 \mathrm{~h}$ earlier, when endogenous glucocorticoid levels were high. It should be noted that Reinberg et al (11) reported a circadian rhythm in the mortality produced by an infectious disease; peak mortality occurred at 06:00, at the end of the patients' resting period.

Pöllmann and Pöllmann (12) studied the efficiency of hepatitis B vaccination. Hospital employees and students in medicine or dentistry were vaccinated against hepatitis B with three injections of vaccine available on the German market. The antibody levels were determined four to eight weeks after the third injection. Figure 3 presents the influence of time of injection on these levels and shows that the afternoon injection (13:00 to $15: 00)$ produced significantly higher antibody 
TABLE 1

Effects of time of day on the pharmacokinetics of antibiotics

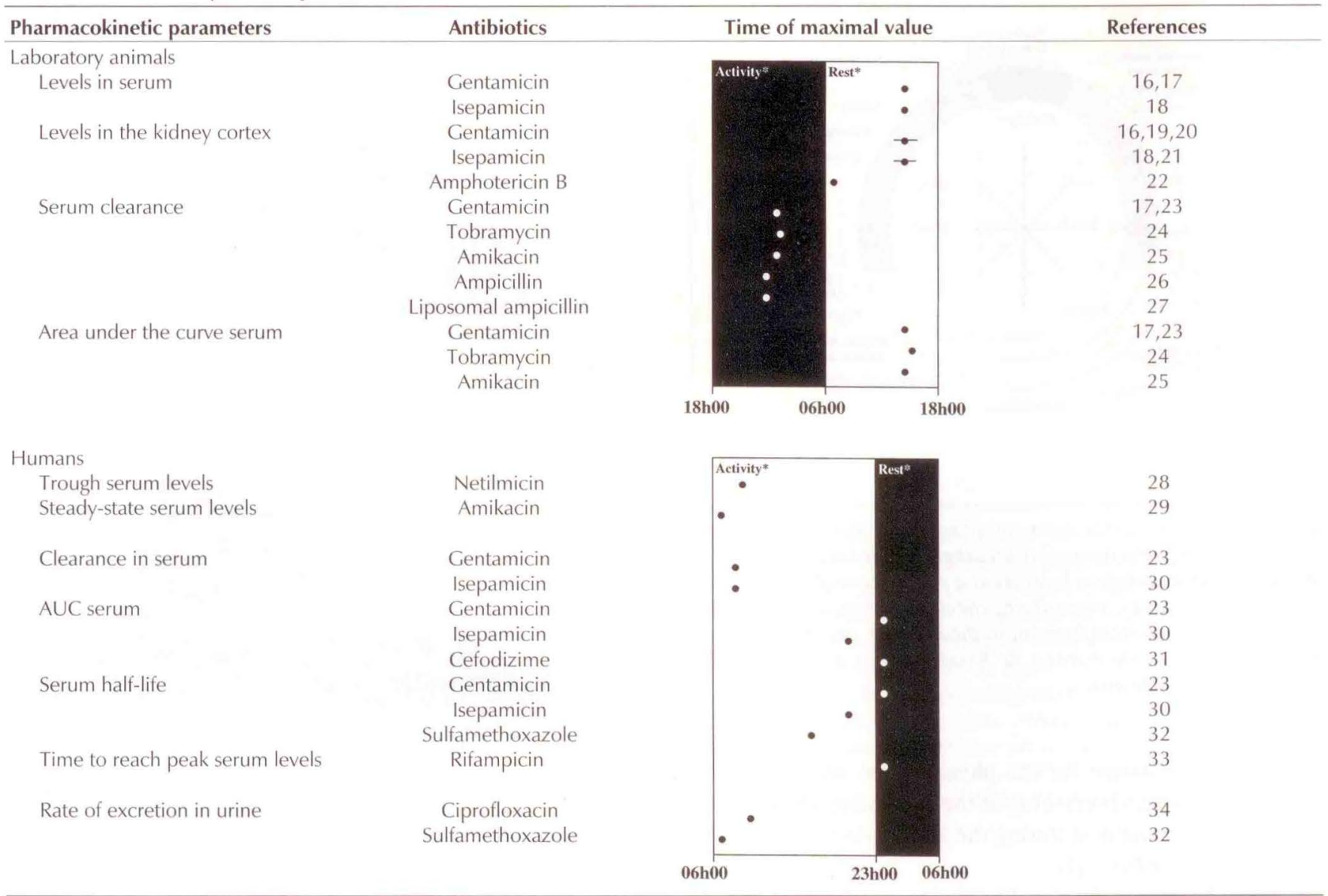

*Black boxes: dark period; white boxes: light period. Laboratory animals are active during the dark period, while humans are active during the light period

levels, especially in the patients with antibody levels larger than $10 \times 10^{3} \mathrm{U} / \mathrm{L}$. Pain and swelling at the injection site were also more frequent when the vaccine was given between 13:00 and 15:00. Season, age, sex and site of vaccination did not significantly influence the antibody levels.

The mechanisms of the time-dependent variations in infectious diseases are not known. However, circadian variations were reported in the Bacille Calmette-Guérin-induced migration of polymorphonuclear lymphocytes (13), in the plasma levels of immunoglobulin A (IgA), IgG, IgM and IgE in the different populations of $\mathrm{T}$ total, $\mathrm{T}$ helper and $\mathrm{T}$ killer lymphocytes (14), as well as in the inflammatory reaction (15).

\section{BIOLOGICAL RHYTHMS IN THE PHARMACOKINETICS OF ANTIBIOTICS}

In recent years, investigators looked at the effect of time of day on the pharmacokinetics and renal toxicity of antibiotics. The objective of these studies was to use the time of antibiotic administration as a tool to reduce the side effects of potentially toxic drugs, such as aminoglycosides. When reviewing data obtained by many investigators, it is necessary to keep in mind that laboratory animals have an activity pattern that is
$12 \mathrm{~h}$ out of phase from that of humans. In other words, rats and mice are active during the night (ie, during the dark phase of the light-dark cycle) and are sleeping during the light phase, when lights are on. Thus, humans are sleeping when rats are active and vice-versa.

Very few investigators have looked specifically at the temporal changes in the pharmacokinetics of antimicrobial agents. Table 1 presents the chronopharmacokinetics of different antibiotics in both laboratory animals and humans. For example, higher peak serum levels of gentamicin $(16,17)$ and isepamicin (18) were found when these drugs were injected in the middle of the rest period of animals. Similar results were observed in the levels of gentamicin $(16,19,20)$ and isepami$\operatorname{cin}(18,21)$ in the renal cortex, while the largest renal cortical content of amphotericin B was found early in the resting period of the animals (22). Table 1 also shows that the maximal serum clearance of gentamicin $(17,23)$, tobramycin (24) and amikacin (25) was found when these antibiotics were injected in the middle of the activity period of rodents. In the cases of ampicillin (26) and liposomal ampicillin (27), maximal clearance was reported to occur during the activity period of animals. In agreement with these data, the area under the serum 
TABLE 2

Effects of time of day on the toxicity of antibiotics

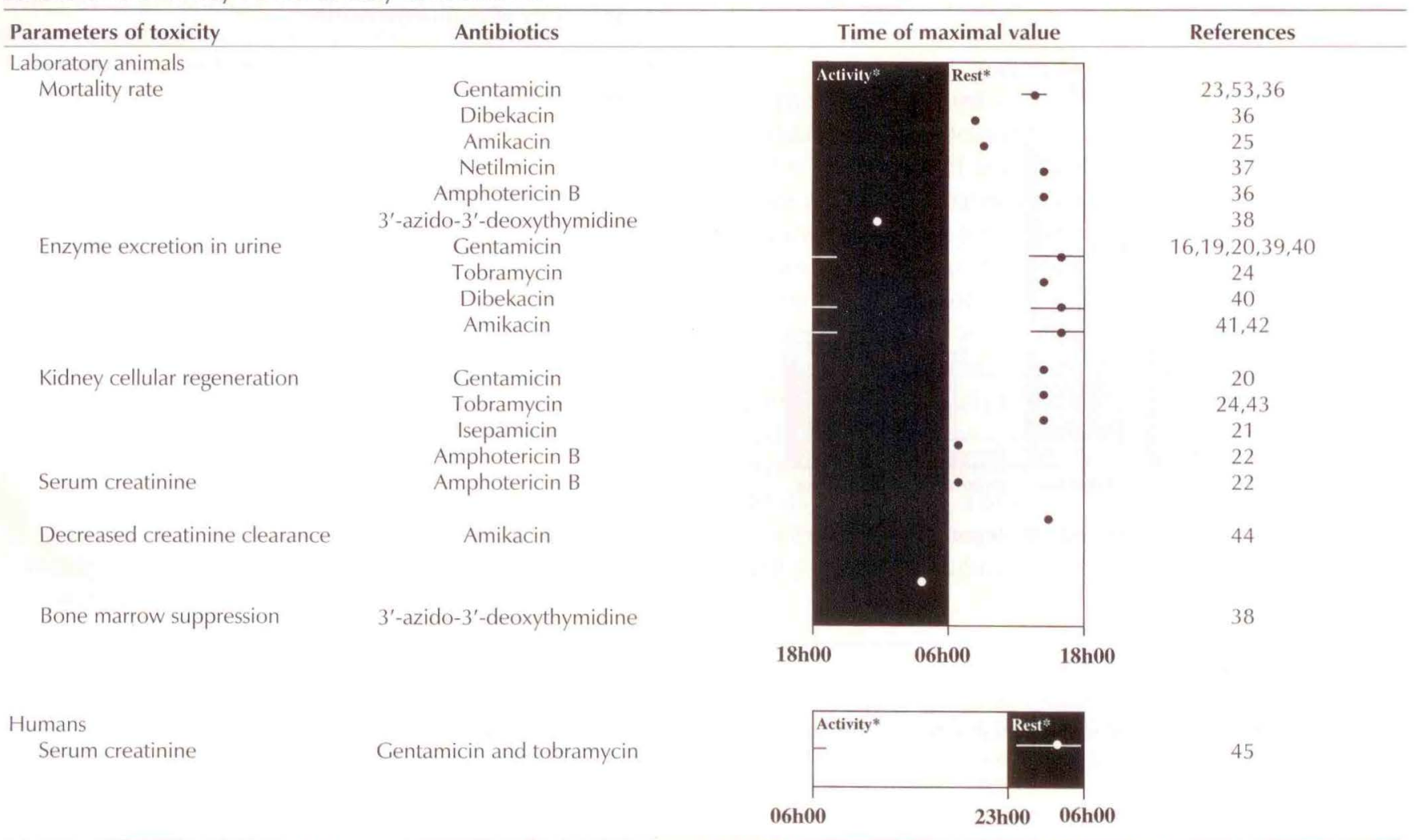

*Black boxes: dark period; white boxes: light period. Laboratory animals are active during the dark period, while humans are active during the light period

curve (AUC) was largest when gentamicin (17,23), tobramycin (24) and amikacin (25) were injected in the middle of the resting period.

The pharmacokinetic data from patients and volunteers are presented in Table 1. Higher trough serum levels were found in the early morning in patients who had normal renal function, but who were suffering from acute severe infections (28). In neutropenic patients receiving continuous infusion of amikacin therapy for infection, levels of amikacin obtained in the early hours of the day were significantly higher than those obtained for the same patient in the evening (29). Table 1 shows that the clearance of gentamicin (23) and isepamicin (30) was higher when these drugs were injected during the activity period, while a longer serum half-life and higher AUC in serum were found after the evening dose. Similar data were found for cefodizime (31) and sulfamethoxazole (32). Other observations suggest that the time to reach peak concentration in serum was longer when rifampicin was injected during the rest period (33). Finally, a higher rate of excretion in urine was found when ciprofloxacin (34) or sulfamethoxazole (32) was injected in the beginning of the activity period. These data are in agreement with previous observations in experimental animals suggesting that the clearance of these drugs is lower during the rest period and higher during the activity period of animals.

\section{BIOLOGICAL RHYTHMS IN THE RENAL TOXICITY OF ANTIBIOTICS}

The effect of time of day on the toxicity of antibiotics was determined mainly in laboratory animals. In a first series of studies, the mortality rate produced by a single injection of antibiotics was investigated. Nakano and Ogawa (35) reported that very large doses of gentamicin killed more mice when injected in the middle of the resting period of the rodents (ie, at 13:00) than at any other time of the day. The data with gentamicin were confirmed by other investigators $(23,35,36)$, and Table 2 demonstrates that temporal variations in the mortality rate were also found after high doses of netilmicin (36), dibekacin (36) and amikacin (25). On the other hand, the mortality rate produced by amphotericin B was maximal when this drug was injected at the beginning of the activity period of laboratory animals (37). Finally, the lethality produced by 3'azido-3'-deoxythymidine (AZT) was significantly higher when it was injected at 24:00, which is the middle of the activity period of rodents, but the largest bone marrow toxicity induced by AZT injection was found $4 \mathrm{~h}$ later at 04:00 (38).

The temporal variations in the acute and chronic renal toxicity produced by low doses of aminoglycosides were investigated in recent years by following the urinary excretion of enzymes such as $N$-acetyl-beta-D-glucosaminidase and betagalactosidase. For example, maximal enzyme excretion in 


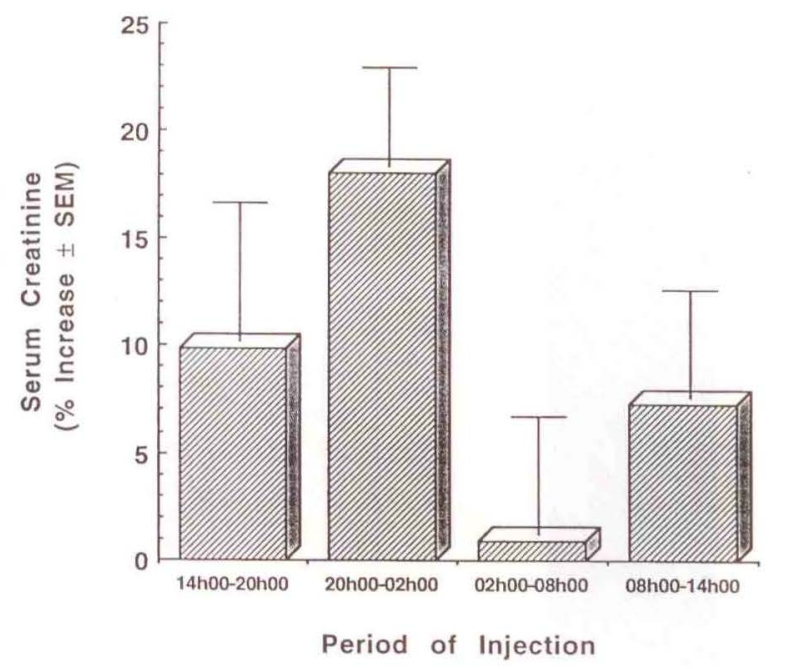

Figure 4) Per cent increase in serum creatinine levels over day $I$ of therapy in 54 hospitalized patients treated with different aminoglycosides at different times of the day. SEM Standard error of mean

urine was obtained when gentamicin $(16,19,20,39,40)$, tobramycin (24), dibekacin $(40)$ and amikacin $(41,42)$ were injected between 13:00 and 20:00. The postnecrotic cellular regeneration measured in the renal cortex was maximal when gentami$\operatorname{cin}(20)$, tobramycin $(24,43)$ and isepamicin $(21)$ were injected at 14:00 compared with any other time of day. In contrast, the cellular regeneration in the renal cortex was found to be maximal at 07:00 in animals given amphotericin B (22). Similarly, the increase in serum creatinine was found to be maximal in rats treated with amphotericin $B$ at 07:00 compared with any other time of day (22). Fujimura et al (44) reported a higher decrease of renal function (decrease creatinine clearance) when amikacin was injected at 16:00 than at other times of the day.

In humans, the effects of the time of day on the renal toxicity of aminoglycosides are difficult to investigate. Thus, a retrospective review of the changes in renal function in 54 hospitalized patients treated with different aminoglycosides was carried out. The percentage increase of serum creatinine over day 1 was used as an index of reduced renal function in patients treated with aminoglycosides at different hours of the day. Patients younger than 16 years of age, those receiving aminoglycosides for less than four days and those receiving a combined therapy with other nephrotoxic drugs were all excluded from the study. Figure 4 shows that the serum creatinine levels increased in patients treated in the evening compared with any other time of day. These data are in agreement with the data obtained in laboratory animals, although no significant difference was found between groups.
TABLE 3

Mechanisms associated with the temporal variations in the renal toxicity of aminoglycosides

\begin{tabular}{|c|c|c|}
\hline Mechanisms & Effects of time of day & References \\
\hline Pharmacokinetics & $\begin{array}{l}\text { Increase serum clearance } \\
\text { during the activity period }\end{array}$ & $17,23-25,30$ \\
\hline $\begin{array}{l}\text { Subcellular distribution in } \\
\text { proximal tubular cells }\end{array}$ & No changes & $21-24$ \\
\hline $\begin{array}{l}\text { Adrenal gland hormones } \\
\text { Food intake }\end{array}$ & No effects & 46 \\
\hline Fasting & $\begin{array}{l}\text { Increase toxicity in fasted } \\
\text { rats during the activity } \\
\text { period }\end{array}$ & 20,47 \\
\hline $\begin{array}{l}\text { Time-restricted } \\
\text { feeding }\end{array}$ & $\begin{array}{l}\text { Minimal toxicity } \\
\text { displaced with period of } \\
\text { food intake }\end{array}$ & 17,48 \\
\hline
\end{tabular}

As this retrospective study was being completed, Prins et al (45) published a prospective clinical trial on the temporal variations in the renal toxicity of aminoglycosides. Patients were randomly separated into three groups with respect to the time of gentamicin or tobramycin therapy. Treatment with aminoglycosides between 00:00 and 07:30 resulted in a significantly higher incidence of renal dysfunction $(35 \%)$ compared with any other time of day.

\section{MECHANISMS ASSOCIATED WITH TEMPORAL VARIATIONS IN THE RENAL TOXICITY OF AMINOGLYCOSIDES}

The mechanisms associated with temporal variations in the renal toxicity of aminoglycosides are not completely understood. Table 3 shows the different potential mechanisms that have been investigated recently. First, temporal variations in the pharmacokinetics of aminoglycosides have been determined by several investigators both in laboratory animals $(17,23-25)$ and in humans $(23,30)$. An increase in serum clearance of these antibiotics observed during the activity period may have contributed significantly to the reduced renal toxicity of aminoglycosides observed during this period of the day (Table 2). Other experiments have shown that the subcellular distribution of tobramycin (24) and isepamicin (21) in proximal tubular cells was similar in animals treated at night and those treated during the day. Furthermore, temporal variations in the serum levels of adrenal gland hormones had no effect on the temporal variations in the renal toxicity of tobramycin (46). In addition, the role of food intake on the circadian variations in the nephrotoxicity of aminoglycosides has not been considered a factor. This potential mechanism was investigated by two different approaches. First, the circadian variations in the renal toxicity of gentamicin was compared in fasted rats versus in rats fed ad libitum. Interestingly, fasting abolished the $24 \mathrm{~h}$ variations in the nephrotoxicity of gentamicin $(20,47)$. Second, the circadian variations in the renal toxicity of gentamicin was studied in three groups of rats that had access to food at different periods. For a brief time, 
the toxicity was minimal when gentamicin was injected during the feeding period, while the maximal toxicity was always found when gentamicin was administered during the fasting period independently of the light-dark cycle (48). Song et al (17) also showed that the manipulation of feeding schedules can modify the rhythm of gentamicin toxicity by changing the rhythm of its kinetics.

\section{BIOLOGICAL RHYTHMS IN THE EFFECTIVENESS OF AMINOGLYCOSIDES}

Very few investigators have looked at the temporal variations in the effectiveness of antibiotics. In an experimental model of pyelonephritis in rats, it was found that gentamicin, given for three and seven days at the time of the least toxicity (ie, 01:00), showed a better efficacy (ie, lower bacterial counts in the kidneys and higher percentage of sterile kidneys) than at other hours of the day (49). By contrast, Hosokawa et al (25) demonstrated that the median effective dose of amikacin in mice infected with Pseudomonas aeruginosa was significantly lower when amikacin was injected in the middle of

\section{REFERENCES}

1. Smolensky MH, Labrecque G. Chronotherapeutics. Pharmaceut News 1997:4:10-7.

2. Dethlefson U, Repges R. Ein neues Therapieprinzip bei Nöchtlichen. Asthma Med Klin 1983;80:40-7.

3. Muller JE, Stone PH, Turi ZG, et al. Circadian variation in the frequency of onset of acute myocardial infarction. N Engl J Med 1985;313:1315-22.

4. Cannon $\mathrm{CP}, \mathrm{McCabe} \mathrm{CH}$, Stone $\mathrm{PH}$, et al. Circadian variations in the onset of unstable angina and non- $\mathrm{Q}$-wave acute myocardial infarction (the TIMI III Registry and TIMI III B). Am J Cardiol 1997;79:253-8.

5. Muller JE, Ludmer PL, Willich SN, et al. Circadian variation in the incidence of sudden cardiac death. Circulation 1987;75:131-8

6. Willich SN, Levy D, Rocco MB, Tofler GH, Stone PH, Muller JE. Circadian variation in the incidence of sudden cardiac death in the Framingham Heart Study population. Am J Cardiol 1987;60:801-6.

7. Tsementzis SA, Gill JS, Hitchcock ER, Gill SK, Beevers DG. Diurnal variation of and activity during the onset of stroke. Neurosurgery 1985;17:901-4.

8. Millar-Craig MW, Bishop CN, Raftery EB. Circadian variation of blood-pressure. Lancet 1978;i:795-7.

9. Halberg F. Temporal coordination of physiologic function. Cold Spring Harbour Quant Biol 1960;25:289-310.

10. Pollmächer T, Mullington J, Korth C, et al. Diurnal variations in the human host response to endotoxin. J Infect Dis 1966; 174:1040-5.

11. Reinberg A, Gervais P, Halberg F, et al. Mortalité des adultes: Rhythmes circadiens et circannuels. Nouv Presse Med 1973;2:289-94.

12. Pöllmann L, Pöllmann B. Circadian variations of the efficacy of hepatitis B vaccination. Ann Rev Chronopharmacol 1988;5:45-8.

13. Bureau JP, Labrecque G, Coupe M, Garrelly L. Influence of BCG administration on the in-vivo migration of leukocytes. Chronobiol Int 1986;3:23-8.

14. Levy F, Canon C, Blum JP, et al. Circadian and or circahemedian rhythms in nice lymphocytes-related variables from peripheral blood of healthy subjects. J Immunol 1985;134:217-22.

15. Labrecque G, Bureau JP, Reinberg AE. Biological rhythms in the inflammatory response and in the effects of non-steroidal anti-inflammatory drugs. Pharmacol Ther 1995;66:285-300.

16. Yoshiyama Y, Kobayashi T, Tomonaga F, Nakano S. Chronotoxical study of gentamicin induced nephrotoxicity in rats. J Antibiot (Tokyo) 1992;45:806-8.

17. Song J, Ohdo S, Ogawa N, Nakano S. Influence of feeding the rest period (13:00), with lower amikacin clearance, than in the middle of the activity period (01:00), with higher amikacin clearance. Further research is needed in this area.

\section{CONCLUSIONS}

The data presented in this review illustrate that temporal variations can be detected in the pharmacokinetics, toxicity and effectiveness of antimicrobial agents. These agents are more rapidly eliminated and are less toxic to laboratory animals when they are injected during the activity period of laboratory animals. The human data are in agreement with data obtained in laboratory animals.

The study of the temporal variations in the pharmacokinetics, toxicity and effectiveness of antimicrobial agents may contribute significantly to increase their efficacy and to reduce toxicity. Moreover, because different likely agents to be given in combination are found to be more toxic at different hours of the day, the injection of these drugs at their respective hours of lowest toxicity should be useful to decrease their toxicity as well as potential additive toxicities.

schedule on chronopharmacological aspects of gentamicin in mice. Chronobiol Int 1993;10:338-48.

18. Yoshiyama Y, Nishikawa S, Sugiyama T, et al. Influence of circadian-stage-dependent dosing schedule on nephrotoxicity and pharmacokinetics of isepamicin in rats. Antimicrob Agents Chemother 1993;37:2042-3.

19. Pariat C, Courtois P, Cambar J, Piriou A, Bouquet S. Circadian variations in the renal toxicity of gentamicin in rats. Toxicol Lett 1988;40:175-82.

20. Beauchamp D, Collin P, Grenier L, et al. Effects of fasting on temporal variations in nephrotoxicity of gentamicin in rats. Antimicrob Agents Chemother 1996;40:670-6.

21. Yoshiyama Y, Grenier L, Gourde P, et al. Temporal variation in nephrotoxicity of low doses of isepamicin in rats. Antimicrob Agents Chemother 1996;40:802-6.

22. LeBrun M, Grenier L, Gourde P, Bergeron MG, Labrecque G, Beauchamp D. Nephrotoxicity of amphotericin B in rats: effects of the time of administration. Life Sci 1996;58:869-76.

23. Nakano S, Song J, Ogawa N. Chronopharmacokinetics of gentamicin: comparison between man and mice. Annu Rev Chronopharmacol 1990;7:277-80.

24. Lin L, Grenier L, Bergeron Y, et al. Temporal changes of pharmacokinetics, nephrotoxicity, and subcellular distribution of tobramycin in rats. Antimicrob Agents Chemother 1994;38:54-60.

25. Hosokawa H, Nyu S, Nakamura K, Mifune K, Nakano S. Circadian variation in amikacin clearance and its effects on efficacy and toxicity in mice with and without immunosuppression. Chronobiol Int 1993;10:259-70.

26. Mesnard-Ricci B, White CA. Chronokinetics of active biliary ampicillin secretion in rats. Chronobiol Int 1998;15:309-21.

27. Pardue RL, White C. Chronokinetics of liposomal encapsulated ampicillin in fasting and nonfasting rats. J Pharma Sci 1996;85:309-12.

28. Lucht F, Tigaud S, Esposito G, et al. Chronokinetic study of netilmicin in man. Eur J Clin Pharmacol 1990;39:199-201.

29. Elting L, Bodey GP, Rosenbaum B, Fainstein V. Circadian variation in serum amikacin levels. J Clin Pharmacol 1990;30:798-801.

30. Yoshiyama Y, Kobayashi T, Ohdo S, et al. Dosing time-dependent changes of pharmacokinetics of isepamicin in man. J Infect Chemother 1996;2:106-9.

31. Jonkman J, Reinberg A, Oosterhuis B, et al. Dosing time and sex-related differences in the pharmacokinetics of cefodizime and in the circadian cortisol rhythm. Chronobiologia 1988; 15:89-102.

32. Ramesh Rao B, Rambhau D. Chronopharmacokinetics of 
sulfamethoxazole in human volunteers. Drug Invest 1992;4:199-204.

33. Avachat MK, Rambhau D, Rao VV, Rao BR, Rao JV. Chronopharmacokinetics of rifampicin. Indian J Physiol Pharmacol 1992;36:251-4.

34. Rao VV, Rambhau D, Rao BR, Srinivasu P. Circadian variation in urinary excretion of ciprofloxacin after a single-dose oral administration at 1000 and 2200 hours in human subjects. Antimicrob Agents Chemother 1997;41:1802-4.

35. Nakano S, Ogawa N. Chronotoxicity of gentamycin in mice. IRCS Med Sci 1982;10:592-3.

36. Pariat $\mathrm{C}$, Cambar J, Courtois P. Circadian variations in the acute toxicity of three aminoglycosides: gentamicin, dibekacin, and netilmicin in mice. Ann Rev Chronopharmacol 1984;1:381-4.

37. Skubitz KM, Wick M, Skubitz A, et al. Timing of amphotericin B therapy is a critical determinant of toxicity. Annu Rev Chronobiol 1986;3:183-6.

38. Zhang R, Lu Z, Diasio C, et al. The time of administration of 3'-azido-3'-deoxythymidine (AZT) determines its host toxicity with possible relevance to AZT chemotherapy. Antimicrob Agents Chemother 1993;37:1771-6.

39. de Lemos E, Pariat C, Piriou A, Fauconneau B, Courtois P. [Circadian variations in the nephrotoxicity of the vancomycin-gentamicin combination in rats]. Pathol Biol (Paris) $1991 ; 39: 12-5$.

40. Pariat C, Cambar J, Piriou A, et al. Circadian variations in the nephrotoxicity induced by high doses of gentamicin and dibekacin in rats. Ann Rev Chronopharmacol 1986;3:107-10.

41. Dorian C, Cambar J. [Circadian variations of amikacin nephrotoxicity in rats]. Pathol Biol (Paris) 1986;34:587-90.
42. Dorian C, Catroux P, Cambar J. [Chrononephrotoxicity of amikacin after 7-day chronic poisoning in rats]. Pathol Biol (Paris) 1987;35:735-8.

43. Lin L, Grenier L, Theriault G, et al. Nephrotoxicity of low doses of tobramycin in rats: effect of the time of administration. Life Sci 1994;55:169-77.

44. Fujimura A, Sudoh T, Ebihara A. Time-dependent change in the toxic effects of amikacin on renal functions. Life Sci 1994;55:367-72.

45. Prins JM, Weverling GJ, van Ketel RJ, Speelman P. Circadian variations in serum levels and the renal toxicity of aminoglycosides in patients. Clin Pharmacol Ther 1997;62:106-11.

46. Beauchamp D, Labrecque G, Bergeron MG. [Is it still possible to reduce the incidence of nephrotoxicity of aminoglycosides?]. Pathol Biol (Paris) 1995;43:779-87.

47. Lin L, Grenier L, LeBrun M, et al. Day-night treatment difference of tobramycin serum and intrarenal drug distribution and nephrotoxicity in rats: effects of fasting. Chronobiol Int 1996;13:113-21.

48. Beauchamp D, Guimont C, Grenier L, et al. Time-restricted feeding schedules modify temporal variation of gentamicin experimental nephrotoxicity. Antimicrob Agents Chemother 1997;41:1468-74.

49. LeBrun M, Grenier L, Gourde P, et al. Effectiveness and toxicity of gentamicin in an experimental model of pyelonephritis: Effect of the time of administration. Antimicrob Agents Chemother 1999;43:1020-6.

50. Haus E, Nicolau GY, Lakatua D, et al. Reference values for chronopharmacology. Ann Rev Chronopharmacol 1988;4:333-424. 


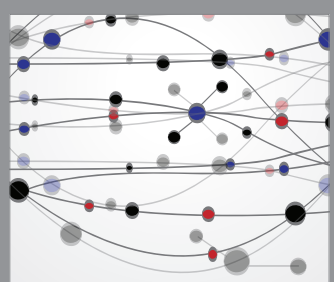

The Scientific World Journal
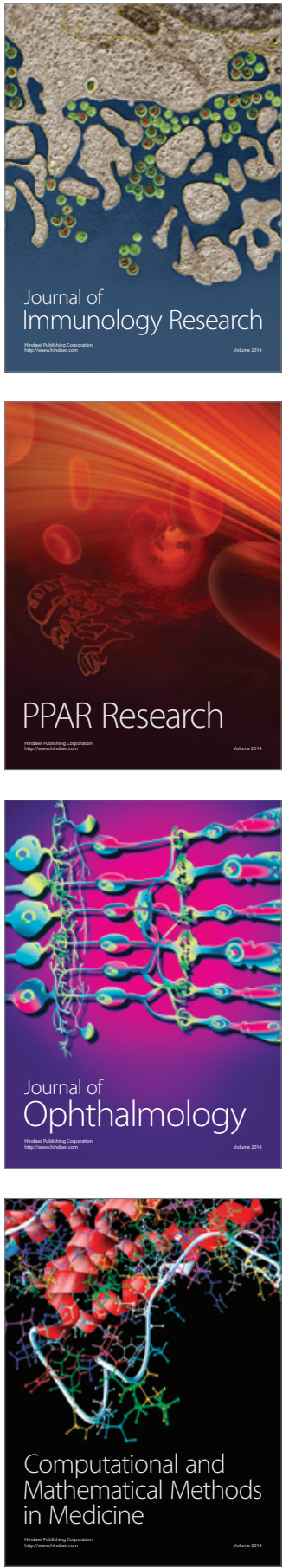

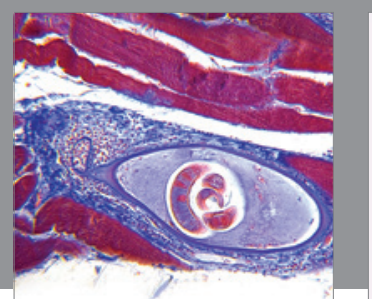

Gastroenterology Research and Practice

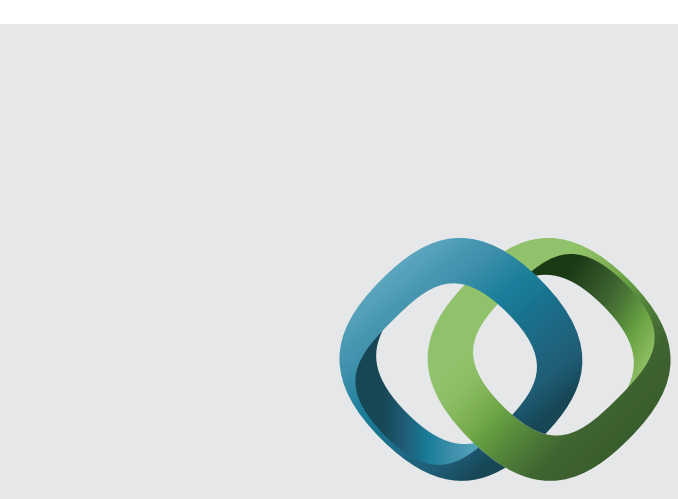

\section{Hindawi}

Submit your manuscripts at

http://www.hindawi.com
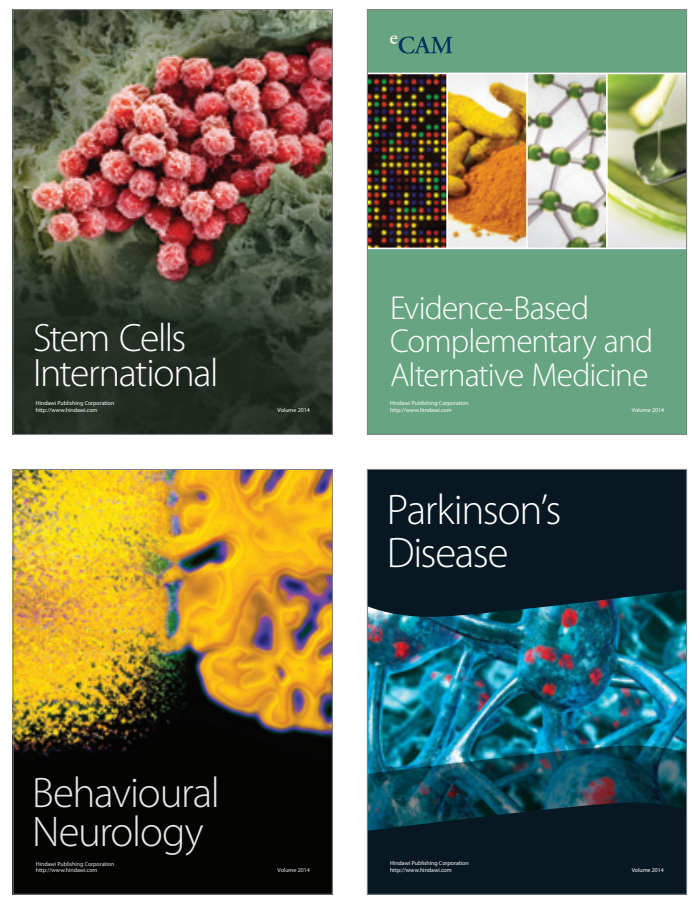
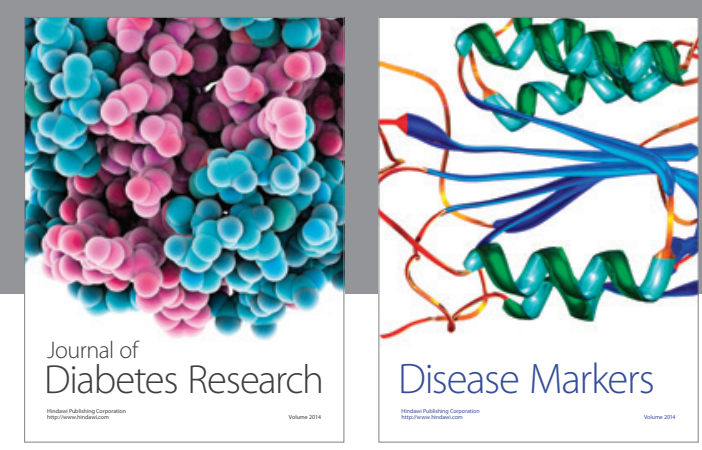

Disease Markers
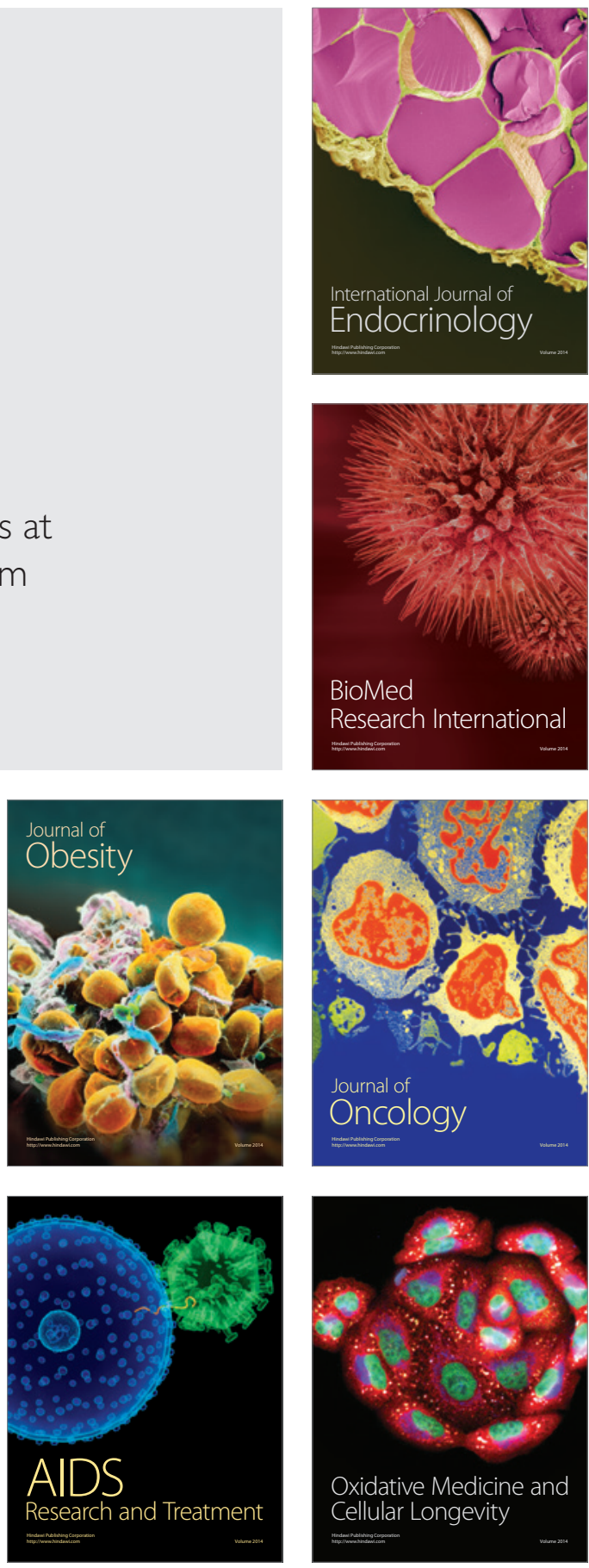